\title{
Time to introduce mentorship into surgical training programmes?
}

\author{
J Edge \\ Division of Surgery, Stellenbosch University, South Africa
}

Corresponding author, email: dr@jennyedge.co.za

I didn't realise it, but as a junior doctor working in New Zealand, I had the privilege of having my first mentor. She was an older woman, Dr Ira, a radiologist from Sri Lanka. At the time, I was working as the only female in the department of general surgery and battling with my male colleagues. After a particularly bruising incident, I went down to see her to complain. She gave me advice I have never forgotten. She introduced me to silence as a reply. It is a powerful weapon. You never regret what you haven't said. It gives you space to contemplate the situation and eventually formulate a reply.

In 2020 the Association of Surgeons of South Africa (ASSA) sent out a questionnaire to all its members. The results have been published in two articles written by Naidu and Buccimazza and published in this edition of the SAJS. The first addresses challenges and barriers to pursuing a career in surgery in South Africa. ${ }^{1}$ The second article elucidates the attitudes toward mentorship among South African general surgeons. ${ }^{2}$ One hundred and twenty-nine respondents took part in the study overall. The majority $(67 \%)$ were specialist surgeons and $18 \%$ registrars. Over half $(53 \%)$ reported having suffered from burnout. ${ }^{1}$ Fiftyfour per cent reported not having a mentor, however, $80 \%$ felt mentorship is an important part of surgical training. ${ }^{2}$

The results of burnout are similar to those reported in other international studies. In a meta-analysis evaluating burnout amongst physicians in the USA, an estimated $67 \%$ reported having had symptoms. ${ }^{3}$ In 2019 , the results from a questionnaire sent to all surgical trainees in the USA were published in NEJM. ${ }^{4}$ They asked about the incidence and source of abuse and discrimination, symptoms of burnout, and frequency of events. Ninety per cent experienced symptoms of burnout in the preceding year; 38.5\% reported experiencing symptoms of burnout within the preceding week. There was an increased incidence of burnout amongst trainees who were subject to discrimination and harassment. Interestingly, the major source of most categories of abuse and discrimination was from patients and patients' families.

As part of a quality improvement process in the Division of Surgery, Stellenbosch University, we conducted a similar anonymous survey in 2019 and 2020. Approximately 20 trainees responded. Specific questions about burnout were not asked but they were asked about incidents of discrimination and verbal abuse and their source. They also reported that the most common source of abuse and discrimination was from patients and their families. They were asked to indicate what the department could do to support them. The introduction of mentoring programmes was amongst the most popular options chosen.
The word mentor was first introduced by Homer in the 8th century in his epic poem the Odyssey. In the poem, Mentor was a friend of Odysseus. When Odysseus was called to war, he asked Mentor to take over the care of his son. And so, the concept of mentoring was formed. There are varied definitions of mentoring, and it can be applied in different ways. Naidu and Buccimazza describe the goal of a mentorship programme "to support and guide individuals through career and leadership development". ${ }^{1}$ Programmes can be introduced on a one-to-one basis or can be run in groups. Many informal initiatives exist within surgical departments, however, the problem with having an informal structure is that extrovert registrars tend to benefit more than introverted registrars.

Whilst watching tennis, the surgeon Atul Gawande asked himself "If Rafael Nadal has a coach, how come lawyers and teachers and journalists don't? Specifically, how come surgeons don't". ${ }^{5}$ Coaching is a self-directed process that is ongoing and facilitated by a trained instructor. Although there are identifiable goals, there are no measurable parameters. In that way, coaching and mentoring are similar.

Most surgical departments in South Africa are unlikely to be able to afford a formal coaching programme. However, why hasn't there been widespread adoption of formal membership programmes within surgical training? There are many reasons cited. The most common objections are from the senior staff within the department. Generally, the people who would be mentors. I believe it is true to say that more attention is paid to the burnout rate among surgical trainees than to that among senior colleagues. There is a perception that adding a mentoring programme in a department adds to their work. Importantly, the study that was done by Naidu and Buccimazza demonstrates that senior surgeons recognise the importance of mentorship programmes and that they too experience burnout.

The fact we work in a resource-constrained setting with exceptionally high trauma volumes places extra burden on all surgeons. COVID-19 has diminished access to health care for our patients and there is a perception that we are all seeing surgical patients with more advanced disease. Although the survey done in our department was too small to claim a causal link to COVID-19, a higher percentage of trainees reported incidences of verbal abuse in 2020 compared to 2019.

There are many tools that can be used for educational purposes. Teaching, mentoring, and coaching are the most employed techniques worldwide. Ubuntu is an African concept that has been used to good effect in selected 
circumstances. ${ }^{6}$ The conventional modality utilised to train a surgeon is teaching with assessment by specialist exit exams. Teaching or training is a formal structured process whereby an individual learns specific skills. There is generally a curriculum that is followed and once the competence has been achieved, the process is complete. Atul Gawande looked for excellence in sport to form his opinion about the need for alternative education modalities that could be implemented to help the process of training a good rather than an ordinary surgeon.

Some of the barriers to choosing a surgical career in South Africa have been illustrated by this local questionnaire. If, as a profession, we are going to be able to continue recruiting bright medical trainees, train them and help them develop the resilience needed for a lasting career, we need to involve them in both identifying problems and working towards solutions. Group mentorship programmes are one way of achieving both: getting suggestions from the "shop floor" and being able to provide guidance and support. ${ }^{7}$ The survey carried out by ASSA is a move in the right direction.

One of the attributes of mentoring is that the mentee may choose their mentor. It may happen informally, as it did to me, and may or not be a person from an aligned profession. There is no doubt that my career path has been altered by the sage words from my mentor, Dr Ira. It behoves all of us in our profession to move on from simply being a teacher and to integrate the principles of mentoring and coaching into our daily surgical practice.

\section{REFERENCES}

1. Naidu P, Buccimazza I. Surgery in South Africa - challenges and barriers. S Afr J Surg. 2021;59(3):77-81. https://doi. org/10/17159/2078-5151/2021/v59n2a3391.

2. Naidu P, Buccimazza I. Surgery in South Africa - the attitudes toward mentorship in facilitating general surgical training. S Afr J Surg. 2021;59(3):82-85.

3. Rotenstein LS, Torre M, Ramos MA, et al. Prevalence of burnout among physicians. A systematic review. JAMA. 2018;320(11):1131-50. https://doi.org/10.1001/jama.2018. 12777.

4. Hu Y-Y, Ellis RJ, Brock Hewitt D, et al. Discrimination, abuse, harassment, and burnout in surgical residency training. $\mathrm{N}$ Engl J Med. 2019;381(18):1741-52. https://doi.org/10.1056/ NEJMsa1903759.

5. The New Yorker 2013. Available from: https://www. newyorker.com/video/watch/atul-gawandedo-surgeons-needcoaches. Accessed 19 Jul 2021.

6. Clutterbuck DA, editor. Case studies of mentoring across the globe, part 1V. The SAGE Handbook of Mentoring. 1st ed. Chapter 31. SAGE.

7. Henry-Noel N, Bishop M, Gwede CK, Petkova E, Szumacher E. Mentorship in medicine and other health professions. J Cancer Educ. 2019;34(4):629-37. https://doi.org/10.1007/ s13187-018-136. 